\title{
Elaboração de doce leite de cabra light ${ }^{1}$
}

\author{
Nara Vanessa dos Anjos Barros², Darkianne Leite da Silva², Maria Aurilene Feitosa de Moura \\ Gonçalves $^{2}$, Gleyson Moura dos Santos ${ }^{3}$, Paulo Víctor de Lima Sousa ${ }^{3}$, Natália Quaresma Costa Melo ${ }^{3}$
}

Resumo: O doce de leite é um produto lácteo produzido basicamente a partir da desidratação do leite líquido e/ou reconstituído, no qual é adicionada a sacarose e submetido à condições de temperatura e pressão, podendo variar de acordo com o fabricante. O objetivo com o presente estudo foi elaborar um doce light de leite de cabra e analisar a composição centesimal (teor de umidade, cinzas, proteínas, lipídios e carboidratos), qualidade microbiológica, aceitação sensorial e preferência do produto. Foram elaboradas duas formulações de doce, sendo uma padrão (controle) e F1 (light, com adição do edulcorante e pectina). As amostras de doce de leite foram analisadas quanto à composição centesimal, qualidade microbiológica (coliformes termotolerantes e pesquisa de Salmonella spp) e as características sensoriais utilizando-se os testes afetivos de escala hedônica e pareado preferência. Obteve-se uma formulação com teor reduzido de carboidratos, que pode ser caracterizada como light para este nutriente. As formulações desenvolvidas estavam de acordo com os padrões microbiológicos estabelecidos pela legislação vigente. Pode-se observar que tanto a amostra padrão como a light de doce de leite de cabra apresentaram uma boa aceitação global e intenção de compra, e não apresentaram diferença significativa $(\mathrm{t}=0,95 ; \mathrm{p}=0,6220)$ entre as mesmas. Diante disto, o produto desenvolvido apresentou uma boa aceitação e viabilidade para a comercialização, com boa qualidade microbiológica, além de apresentar uma redução no teor de carboidratos, tornando-se uma opção para os indivíduos que necessitam de alimentos para fins especiais ou que buscam uma alimentação mais saudável.

Palavras-chave: Alimento; Animal caprino; Edulcorante.

\section{Elaboration of goat light milk sweet}

\begin{abstract}
Dulce de leche is a dairy product basically produced from the dehydration of liquid and/or reconstituted milk, in which sucrose is added and subjected to conditions of temperature and pressure, which may vary according to the manufacturer. The objective of the present work was to elaborate a goat milk sweet light and and analyze the chemical composition (moisture content, ash, protein, lipids and carbohydrates), microbiological quality, the sensory acceptance and preference of the product. Two sweet formulations were made, one standard (control) and F1 (light, with the addition of sweetener and pectin). The sweet milk samples were analyzed for chemical composition, microbiological quality (thermotolerant coliforms and Salmonella spp) and sensory characteristics using affective hedonic scale test and paired preference. A formulation with a reduced carbohydrate content was obtained, which can be characterized as light for this nutrient. The formulations developed were in accordance with the microbiological standards established by current legislation. It can be observed that both the standard and the light sample of goat milk sweet light presented a good overall acceptance and purchase intention and did not show significant difference $(t=0.95 ; \mathrm{p}=0.6220)$ between them. Given this, the product developed presented a good acceptance and viability for commercialization, with good microbiological quality, besides presenting a reduction in the carbohydrate content, becoming an option for the individuals who need food for special purposes or for those seeking a healthier diet.
\end{abstract}

Keywords: Food; Goat animal; Sweetener.

\footnotetext{
${ }^{1}$ Submetido em 06/02/2020 e aprovado em 11/12/2020;

${ }^{2}$ Universidade Federal do Piauí, Campus Senador Helvídio Nunes de Barros, Picos, Piauí, Brasil; E-mail: naranessa@ufpi.edu.br (Autor correspondente) - ORCID: https://orcid.org/0000-0003-2044-7064; arkianneleitte@gmail.com; ORCID: https://orcid.org/0000-0001-69909149; aurilene52@live.com; ORCID: https://orcid.org/0000-0002-5121-4397;

${ }^{3}$ Universidade Federal do Piauí, Campus Universitário Ministro Petrônio Portella, Teresina, Piauí, Brasil; E-mail: g_leyson_moura@hotmail.com - ORCID: https://orcid.org/0000-0003-0904-1995; paulovictor.lima@hotmail.com - ORCID: https://orcid.org/0000-0003-1486-0661; natalia_quaresma@hotmail.com - ORCID: https://orcid.org/0000-0002-8647-3698
} 


\section{Introdução}

O leite de cabra é um produto oriundo da ordenha de animais sadios de Capra aegagrus hircus (cabra), de composição química similar ao leite de vaca, que fornece nutrientes como minerais, vitaminas, proteínas de fácil digestão, aminoácidos com adequado perfil nutricional e ácido graxo essencial. O diferencial entre os dois tipos de leite é que a porção lipídica do leite caprino apresenta menor tamanho dos glóbulos de gordura, resultando em melhor textura dos produtos beneficiados, com $28 \%$ de glóbulos de gordura e com diâmetro igual ou inferior a 1,5 microns. Esta característica confere ao leite de cabra alta digestibilidade, diminuindo o tempo de trânsito intestinal (Alves et al., 2017; Coelho et al., 2018).

O doce de leite é um produto lácteo produzido basicamente a partir da desidratação do leite líquido e/ou reconstituído, no qual é adicionada a sacarose e submetido à condições de temperatura e pressão, podendo variar de acordo com o fabricante. $\mathrm{O}$ bicarbonato de sódio também pode ser adicionado no momento do preparo do doce de leite com o intuito de promover a coloração amarronzada, típica de compostos gerados a partir reação de Maillard, que é favorecida quando o pH do doce de leite se encontra entre 6,0 e 7,0. Além disso, essa adição impede o desenvolvimento de grumos resultantes da desestabilização da caseína, produzida quando compostos ácidos são concentrados durante o processo de evaporação (Perrone et al., 2011).

Esse produto tem como característica uma coloração marrom, sabor e aroma típicos, que são resultantes da Reação de Maillard, que provoca o escurecimento no alimento decorrente da descoloração provocada pela reação entre carbonila e os grupos amina livre, incidindo sobre o desenvolvimento do pigmento melanoidina. Assim, esta reação decorre da complexação dos aminoácidos presentes no leite e dos açúcares redutores (Alburquerque et al., 2011).

Atualmente, existem também doce de leite na versão diet $e$ light, sendo utilizada uma formulação mais complexa, para que nesta opção o produto adquira um bom corpo, sabor, doçura e rendimento característicos da versão tradicional. Já para conferir corpo ao doce podem-se utilizar fibras solúveis, polidextroses, fruto oligossacarídeos, gelatina, pectina, entre outros.
Outra opção é o doce de leite de soja para consumidores intolerantes à lactose (Garcia e Carvalho, 2011).

Sabendo que o leite de cabra é um alimento de elevado valor nutritivo e, no entanto, pouco consumido pela população brasileira, sendo às vezes desperdiçado, a utilização dessa matériaprima para o desenvolvimento de novos produtos surge como uma opção de aproveitamento, valorizando assim seus benefícios, já que o mesmo possui excelentes quantidades de macro e micronutrientes, além de uma melhor digestibilidade. Assim, com esta pesquisa se propôs desenvolver um doce light de leite à base de leite de cabra.

\section{Material e Métodos}

\subsection{Local e obtenção da matéria-prima}

O leite de cabra foi obtido utilizando-se de três animais caprinos sem raça definida (SRD), pertencentes à comunidade Quem-Diria, localizada na cidade de Jatobá-PI. As cabras foram alojadas em uma área com dimensões de $5,0 \times 10,0 \mathrm{~m}$, contendo bebedouro e comedouro. A alimentação foi constituída de capim e suplemento mineral 75 específico para cabras. As amostras de leite foram obtidas por meio de ordenha manual e higiênica e então envasadas em potes plásticos de polietileno individuais com capacidade de 1 litro, os quais foram armazenados sob refrigeração $\left(7^{\circ} \mathrm{C}\right)$, até a hora da sua utilização. As demais matérias-primas utilizadas na elaboração do produto que incluíram o açúcar demerara, o edulcorante esteviosídeo e pectina, foram obtidos no comércio varejista da cidade de Picos-PI.

\subsection{Processamento dos doces}

Foram elaboradas duas formulações de doce, sendo a padrão $\mathrm{P}$ (controle), em que se utilizou o leite de cabra e açúcar demerara como matériasprimas (Tabela 1) e a F1, na qual foi utilizado o leite de cabra, açúcar demerara, edulcorante esteviosídeo e pectina para a possível manutenção de textura e cor do doce, no qual as proporções foram testadas até a obtenção de um produto viável sensorialmente para posteriores análises sensoriais pelos assessores. A F1 apresentou redução de $27,8 \%$ de carboidratos, podendo ser considerada light (mínimo de $25 \%$ de redução) para este macronutriente, que foi confirmada após as análises da composição centesimal, na qual a 
formulação padrão apresentou $49 \%$ de carboidratos, e a F1 com $35,4 \%$ deste macronutriente.

Tabela 1 Porcentagem das matérias-primas usadas nas formulações padrão (P) e de doce light (F1) de leite de cabra

\begin{tabular}{lcc}
\hline \multicolumn{1}{c}{ Matéria-prima } & \multicolumn{2}{c}{ Quantidade (\%) } \\
& $\mathrm{P}$ & $\mathrm{F} 1$ \\
\hline Leite de cabra & 86,0 & 84,7 \\
Açúcar demerara & 10,8 & 7,0 \\
Edulcorante & - & 5,1 \\
Pectina & 3,2 & 3,2
\end{tabular}

Legenda: P - Formulação padrão; F1 - Formulação de doce light de leite de cabra.

Após a obtenção do leite de cabra, o mesmo foi coado, colocado em uma panela, o qual foi submetido ao fogo em temperatura de $120^{\circ} \mathrm{C}$. Para a formulação $\mathrm{P}$, após iniciar a fervura, adicionou-se o açúcar demerara. Já para a para a formulação F1 (light), foi adicionada após a fervura do leite, o açúcar demerara, o edulcorante e a pectina, necessitando de homogeneização com uma concha. O processo de cocção teve duração em torno de 2 horas, até que se obtivesse um ponto desejável, o qual foi verificado através de duas diferentes formas: a primeira pela determinação do teor de sólidos solúveis (acima de $66{ }^{\circ}$ Brix) e a segunda correspondeu à investigação subjetiva de liberação de pequena quantidade de doce em copo de água (Perrone et al., 2011). Posteriormente, ao preparo das formulações padrão e light (F1), estas foram retiradas das panelas e colocadas em recipientes de vidro até o resfriamento. Após essa etapa, os doces foram armazenados em recipientes de vidro com tampas, ao abrigo de luz, em temperatura ambiente, até o momento das análises.

\subsection{Aspectos Éticos}

O projeto foi submetido ao Comitê de Ética e aprovado quanto a seus aspectos éticos e metodológicos pelo Comitê de Ética em Pesquisa da UFPI (parecer de $\mathrm{n}^{\circ}$ 0178.0.045.000-09). Todos os participantes assinaram o Termo de Consentimento Livre Esclarecido (TCLE) antes da realização da análise sensorial, segundo as diretrizes da resolução $\mathrm{n}^{\circ} 466$, de 12 de dezembro de 2012 (Brasil, 2012).

\subsection{Análise sensorial}

A análise sensorial foi realizada no Laboratório de Análise Sensorial de Alimentos da
Universidade Federal do Piauí - CSHNB. A aplicação dos testes ocorreu das 9:00-14:00 h. Os testes sensoriais foram realizados com 100 avaliadores não treinados. As amostras foram servidas em copos descartáveis de $50 \mathrm{~mL}$, codificados com três dígitos, com quantidades padronizadas (25 g), acompanhados de uma colher descartável e água filtrada natural, para limpeza do palato entre a avaliação das amostras. Foi utilizado o delineamento de blocos completos, de forma monádica. A ordem de apresentação foi balanceada, de forma que cada amostra foi apresentada em igual número de vezes e em cada posição (Dutcosky, 2013).

Para analisar a aceitação dos produtos, foi aplicado o teste de Escala Hedônica, onde os assessores julgaram as amostras e atribuíram notas que variaram de 1 a 9 ao produto, sendo para o requisito desgostei muitíssimo (nota 1) a gostei muitíssimo (nota 9). $\mathrm{Na}$ análise de preferência, utilizou-se o teste de comparação pareada, o qual as amostras foram apresentadas aos pares, e solicitado ao avaliador que escolhesse a amostra de sua preferência. Avaliou-se também a intenção de compra dos produtos, com uma escala que variou entre 1 (certamente não compraria) e 5 (certamente compraria) (Dutcosky, 2013).

Calculou-se ainda, o Índice de Aceitabilidade (IA) do produto, pela fórmula, $\mathrm{IA}=(\mathrm{A} / \mathrm{B}) \times 100$, onde $\mathrm{A}=$ Nota média obtida para o produto, e $\mathrm{B}$ = Nota máxima dada ao produto. Para que um produto seja considerado bem aceito pelos assessores, o índice de aceitabilidade deve ser > 80\% (Dutcosky, 2013).

\subsection{Análises da composição centesimal}

Foram determinados o teor de umidade por secagem em estufa a $105^{\circ} \mathrm{C}$, as cinzas por incineração em forno mufla a $550^{\circ} \mathrm{C}$, proteínas pelo método de macro Kjeldahl, lipídeos utilizando extrator de Soxhlet e carboidratos por diferença dos demais constituintes, conforme metodologia estabelecida pela AOAC (Association of Official Analytical Chemists) (2005). E o valor energético total por meio de valores de conversão (Watt e Merrill, 1963).

\subsection{Análises microbiológicas}

Foram analisados os coliformes à $45^{\circ} \mathrm{C}$ (Coliformes termotolerantes) por meio do método dos tubos múltiplos cujo resultado é expresso em

Agropecuária Técnica, Areia-PB, v. 41, n. 3-4, p. 109-117, 2020

https://doi.org/10.25066/agrotec.v41i3-4.50587 
"Número Mais Provável" por grama da amostra (NMP/g) e Salmonella sp., cujo resultado é expresso em Unidades Formadoras de Colônias (UFC/g). Inicialmente, foram pesados assepticamente $25 \mathrm{~g}$ de cada amostra e acondicionadas a $225 \mathrm{~mL}$ de água peptonada a 0,1 $\%$. Em seguida, realizaram-se as diluições decimais seriadas em água peptonada $10^{-2}$ e $10^{-3}$ (Apha, 2001).

Os resultados obtidos para as análises de coliformes a $45{ }^{\circ} \mathrm{C}$ e Salmonella spp. foram comparados aos valores preconizados pela Resolução da Diretoria Colegiada (RDC) - $\mathrm{n}^{\circ} 12$, de 2 de janeiro de 2001 (Brasil, 2001), pois apesar de haver uma nova resolução RDC no 331/2019 (Brasil, 2019), esta não foi considerada no presente estudo porque em seu artigo 20 estabelece que os produtos fabricados até a data de 26/12/2019 deverão cumprir os padrões microbiológicos estabelecidos pela $\mathrm{RDC} \mathrm{n}^{\circ} 12$, de 2 de janeiro de 2001, até o fim de seus prazos de validade.

\subsection{Análise estatística dos dados}

Todas as análises químicas e microbiológicas foram realizadas em triplicata. Nos testes sensoriais, foi utilizado o delineamento em blocos completos casualizados com 2 repetições. Utilizou-se a técnica de apresentação em blocos completos, ou seja, as duas amostras foram apresentadas simultaneamente. A ordem de apresentação das amostras foi balanceada de forma a evitar víeis nos resultados. Os resultados das análises químicas e microbiológicas foram expressos como a média das três repetições e respectivo desvio-padrão (DP) e submetidos ao teste $t$ de Student para verificar as diferenças entre as duas formulações desenvolvidas, admitindo-se erro de até $5 \%$ de probabilidade de erro e intervalo de confiança (IC) de 95\%. Para tal, utilizou-se o programa estatístico Assistat versão 7.7 (Silva e Azevedo, 2006). Além disso, alguns resultados foram expressos na forma de médias e porcentagens, na forma de Tabelas e/ou Figuras.

\section{Resultados e Discussão}

$\mathrm{Na}$ Tabela 2, observa-se a composição centesimal e o valor energético total para as formulações desenvolvidas. O leite light diferiu do padrão, pois apresentou menores teores de proteínas e lipídeos, e um maior teor de água total.

Tabela 2 Valores médios \pm desvio padrão da composição centesimal e valor energético total (VET) do doce de leite padrão (P) e light (F1) formulados a partir do leite de cabra

\begin{tabular}{|c|c|c|c|}
\hline \multicolumn{4}{|c|}{ Doce de leite } \\
\hline Parâmetros & $\mathrm{P}$ & F1 & Valor de F (probabilidade) \\
\hline Umidade & $30,4 \pm 0,65^{\mathrm{a}}$ & $46,2 \pm 1,15^{\mathrm{b}}$ & $5,25(0,0003)$ \\
\hline Cinzas & $1,9 \pm 0,00^{\mathrm{a}}$ & $1,85 \pm 0,10^{\mathrm{a}}$ & $2,34(0,0541)$ \\
\hline Proteínas & $11,2 \pm 0,0^{\mathrm{a}}$ & $10,5 \pm 0,07^{\mathrm{b}}$ & $3,30(0,0143)$ \\
\hline Lipídios & $7,5 \pm 0,07^{\mathrm{a}}$ & $6,0 \pm 0,14^{b}$ & $1,29(0,0017)$ \\
\hline Carboidratos & 49,0 & 35,4 & - \\
\hline Valor Energético Total (VET) & 280,3 & 237,6 & - \\
\hline
\end{tabular}

Letras subscritas minúsculas iguais entre as formulações não há diferença significativa entre as médias segundo teste $t$ de Student, ao nível de 5\% de probabilidade.

Comparando os teores obtidos da composição centesimal com a legislação de doce de leite, Portaria $\mathrm{n}^{\circ} 354$, de 04 de setembro de 1997 (Brasil, 1997), que estabelece um teor máximo de $30 \%$ de umidade, máximo de $2 \%$ de cinzas, mínimo de 5\% de proteínas e 6 a 9\% de lipídeos, as formulações desenvolvidas estão de acordo com a legislação vigente com exceção da umidade. Pieretti et al. (2012) encontraram teores de umidade inadequados segundo à legislação brasileira, que variaram de $41,5 \%$ a $49,1 \%$ em amostras de doce de leite com adição de concentrações de açúcar mascavo. No presente estudo, a adição de pectina a formulação $\mathrm{F} 1$ pode ter aumentado o teor de água da amostra, pois esta tem propriedade geleificante e promove maior retenção de água (Santi et al., 2014).

A formulação 1 desenvolvida pode ser considerada light porque apresentou um porcentual de redução superior a $25 \%$ com relação aos carboidratos, em relação à amostra padrão (formulação padrão apresentou $49 \%$ de carboidratos, e a F1 35,4\%; assim, a redução porcentual foi de aproximadamente $28 \%$ deste macronutriente) (Brasil, 1998). Além disso, a 
formulação elaborada apresentou como aspectos positivos uma redução no teor de lipídeos e no VET, tornando-se uma opção para os indivíduos que necessitam de dietas com restrição.

Na Tabela 3 estão apresentados os resultados das análises microbiológicas das amostras.

Tabela 3 Resultados da análise microbiológica realizada no doce de leite padrão (P) e light (F1) formulados a partir de leite de cabra

\begin{tabular}{ccc}
\hline Doce de leite & $\begin{array}{c}\text { Coliformes a } \\
45^{\circ} \mathrm{C} \\
\left(\mathrm{NMP} . \mathrm{mL}^{-1}\right)^{*}\end{array}$ & $\begin{array}{c}\text { Salmonella spp } \\
(25 \mathrm{~mL}) \\
(\mathrm{P} / \mathrm{A}) * *\end{array}$ \\
\hline $\mathrm{P} 1$ & $<3$ & Ausente \\
$\mathrm{F} 1$ & $<3$ & Ausente \\
\hline Padrão da & $10^{2}{\mathrm{NMP} . \mathrm{mL}^{-1}}^{*}$ & Ausente \\
legislação & & \\
(Brasil, 2001) & & \\
*NMP/mL ${ }^{-1}=$ Número Mais Provável por miligramas; ** P/A $=$ \\
Presente/Ausente
\end{tabular}

As duas formulações desenvolvidas obtiveram contagens de coliformes inferiores a $3 \mathrm{NMP} / \mathrm{g}$ e ausência de Samonella spp, atendendo aos padrões microbiológicos para alimentos segundo a Resolução RDC nº 12 (Brasil, 2001).

Segundo Costa et al. (2016), são escassas na literatura e legislação brasileira uma padronização no processamento ou qualidade de doces de leite, fato que se torna mais grave, à medida que não há para doces de leite à base de leite de cabra. Além disso, o doce de leite é um produto de características variáveis de região para região no Brasil e produzido inclusive em áreas rurais, o que dificulta a comparação dos dados entre os estudos.

Os resultados obtidos na análise sensorial das duas formulações de doce de leite de cabra, relacionadas à aceitação global obtida pela escala hedônica, intenção de compra e índice de aceitabilidade estão apresentados na Tabela 4. Pode-se observar que tanto a amostra padrão como a light de doce de leite de cabra apresentaram uma boa aceitação global e intenção de compra, pois não apresentaram diferença significativa entre as mesmas, de acordo com o teste de $\mathrm{t}$ de Student ao nível de $5 \%$ de probabilidade.

O teste de escala hedônica é um método afetivo que avalia de forma subjetiva o quanto o provador gostou ou desgostou do produto, no qual notas acima de 6 são indicativas de boa aceitação
(Dutcosky, 2013). Pode-se observar que tanto a amostra padrão como a light de doce de leite de cabra apresentaram uma boa aceitação global e intenção de compra, sem diferença significativa $(\mathrm{p}<0,05)$ entre as mesmas, de acordo com o teste de Tukey ao nível de 5\% de probabilidade. A média de notas obtidas para a aceitação global (P - 7,2; F1 - 7,4) dos produtos desenvolvidos no presente estudo foram superiores aos obtidos por Granda et al. (2005), que desenvolveram em seu estudo três formulações de doce de leite em pasta, sendo a primeira com acréscimo de sacarose (doce comum: F1) e as outras com os seguintes edulcorantes: acesulfame-K e sucralose na segunda formulação (F2); e ciclamato de sódio, esteviosídeo, sacarina sódica e sorbitol na terceira (F3). Granda et al. (2005) verificaram boa aceitação para o atributo impressão global das formulações F2 e F3, com médias de 6,4 e 6,6 para F2 e F3, respectivamente.

Tabela 4 Médias de notas de aceitação global, intenção de compra e índice de aceitabilidade de formulações padrão (P) e light (F1) de doce de leite de cabra

\begin{tabular}{lcc}
\hline \multicolumn{1}{c}{ Testes } & $\mathrm{P}$ & $\mathrm{F} 1$ \\
\hline Aceitação global & $7,2 \mathrm{a}$ & $7,4 \mathrm{a}$ \\
Intenção de compra & $3,9 \mathrm{a}$ & $4,2 \mathrm{a}$ \\
Índice de aceitabilidade $(\%)$ & 80,0 & 82,0 \\
\hline
\end{tabular}

*Letras subscritas minúsculas iguais entre as formulações não há diferença significativa entre as médias segundo teste t de Student, ao nível de 5\% de probabilidade.

No estudo de Milagres et al. (2010) foram elaboradas três formulações de doces: doce com adição de açúcar (A), com edulcorante sucralose (B) e doce com ciclamato, sacarina e sorbitol (C). $\mathrm{Na}$ análise sensorial dos atributos sabor, textura e impressão global por meio da escala hedônica, os doces $\mathrm{B}$ e $\mathrm{C}$ obtiveram notas médias que ficaram na faixa de 4,4 a 6,6, ou seja, notas hedônicas inferiores as verificadas no presente estudo para a formulação F1. Para Milagres et al. (2010), a aceitação mais baixa principalmente em relação aos atributos impressão global e textura dos doces sem açúcar pode ser explicada pela cor mais clara e menor dureza desses. Nessas formulações, a ausência de sacarose diminui a reação de Maillard, reação química responsável pelo sabor, aroma e cor dos doces de leite.

Costa et al. (2016) produziram três formulações de doces de leite de cabra acompanhadas de calda de café, com adição de níveis diferentes de açúcar, sendo eles: 20, 30 e 
40\%. Comparando-se os dados do presente estudo com os obtidos por Costa et al. (2016), a F1 apresentou média de aceitação similar às formulações elaboradas por Costa et al. (2016), o qual obtiveram médias de notas de 7,6 para o atributo sabor na formulação com $20 \%$ de adição de açúcar.

Segundo Dutcosky (2013), para um produto ser aceito pelos assessores deve atingir uma porcentagem maior ou igual a $80 \%$ no índice de aceitabilidade (IA). Assim, pelos resultados obtidos (Tabela 4), todas as formulações avaliadas de doce de leite de cabra obtiveram adequada IA. Com relação ao IA, a formulação de doce light de leite de cabra obteve maior índice em comparação à amostra padrão, o que pode ser justificado pelo fato de tratar-se de um produto de sabor diferenciado, além do mais, pode-se observar que não houve interferência com relação ao gosto residual do edulcorante que foi adicionado na formulação light.

Sabe-se que um produto que não apresenta satisfatórios resultados em teste de aceitação com o consumidor, provavelmente, falhará quando for para o comércio, a despeito do marketing feito sobre ele, pois as características sensoriais, geralmente, estão em primeiro lugar para o consumidor (Silva et al., 2019).

Na Figura 1 está apresentado o histograma com os resultados da escala hedônica das formulações padrão e de doce light de leite de cabra, o qual observa-se que F1 obteve mais notas de aceitação, com destaque para as notas 7 (gostei moderadamente), 8 (gostei muito) e 9 (gostei muitíssimo). Essa formulação, de acordo com o teste de escala hedônica de nove pontos, os atributos avaliados "gostei muitíssimo", "gostei muito", "gostei moderadamente" e "gostei ligeiramente", atingiram um porcentual de $86 \%$ e com os demais itens, "nem gostei, nem desgostei", "desgostei ligeiramente", "desgostei moderadamente", "desgostei muito", e "desgostei muitíssimo", representando a menor parte de $14 \%$.

Em relação aos resultados do teste de comparação pareada (Tabela 5), a amostra padrão obteve um porcentual de preferência de $55 \%$ enquanto a formulação light obteve $45 \%$ de preferência, não havendo diferença estatística significativa entre as amostras a um nível de 5\% de probabilidade. Contudo, de acordo com a tabela do teste de Comparação Pareada (Palermo, 2015), se a soma da amostra indicada como preferida for igual ou maior ao mínimo tabelado, conclui-se que há diferença significativa de um produto em relação ao outro ao nível de $5 \%$ de significância. Apesar de 55\% dos provadores terem escolhido a amostra de doce de leite padrão, não houve preferência pelas amostras, pois o número de preferência para esse doce foi menor que o mínimo tabelado (igual a 61).

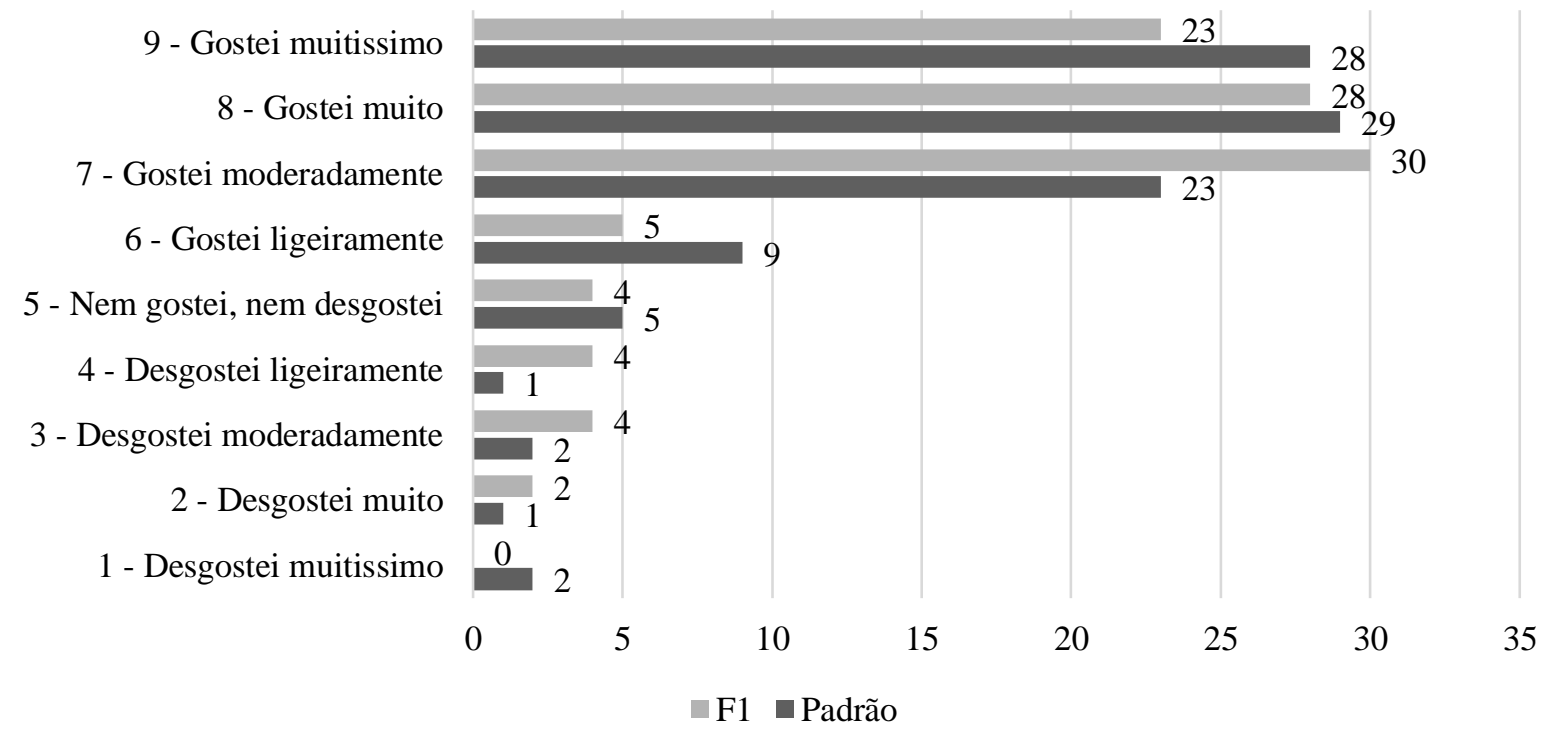

Figura 1 Aceitação global por nota das formulações padrão e light de doce de leite de cabra (F1), segundo o teste de escala hedônica de nove pontos. 
Tabela 5 Teste de comparação pareada das formulações padrão e light de doce de leite de cabra

\begin{tabular}{lccc}
\hline Formulação & $\begin{array}{c}\text { Número } \\
\text { de } \\
\text { assessores }\end{array}$ & $\begin{array}{c}\% \text { de } \\
\text { preferência }\end{array}$ & $\begin{array}{c}\text { Número } \\
\text { tabelado* }\end{array}$ \\
\hline $\mathrm{P}$ & 55 & 55,0 & 61 \\
$\mathrm{~F} 1$ & 45 & 45,0 & \\
TOTAL & 100 & 100 & \\
\hline * Palermo (2015) & & &
\end{tabular}

Observaram-se resultados similares ao da presente pesquisa no estudo de Ribeiro et al (2019). Estes autores elaboraram duas formulações de doce de leite: uma convencional e outra diet (com adição de sucralose, Litesse ${ }^{\circledR}$ e Lactitol®). Não houve diferenças significativas $(\mathrm{p}<0,05)$ no teste de comparação pareada das duas formulações. Entretanto, os autores apontaram uma tendência dos provadores em escolherem o doce de leite diet, que poderia estar relacionada com a melhor cor e melhor impressão global desse produto.
Quanto aos comentários dos avaliadores, estes justificaram a preferência pela amostra padrão relatando que a amostra em questão apresentava uma coloração mais vibrante, uma textura mais homogênea e um sabor mais doce. De acordo com Ferreira (2012), a diferenciação de cor no produto final pode ocorrer em função de vários fatores, dentre eles: a acidez inicial do leite, a quantidade e o momento da adição do bicarbonato de sódio, a presença de açúcares redutores além da lactose, o teor inicial e final de sólidos solúveis da calda (leite mais sacarose) e do doce de leite, respectivamente, o tempo gasto para a evaporação e a pressão de vapor utilizada nos tachos. O maior teor de sólidos solúveis no início do processo diminui o tempo de fabricação contribuindo para obtenção de um produto mais claro.

Na Figura 2, é apresentado o histograma dos resultados da análise sensorial em relação à intenção de compra pela escala de cinco pontos para as duas amostras.

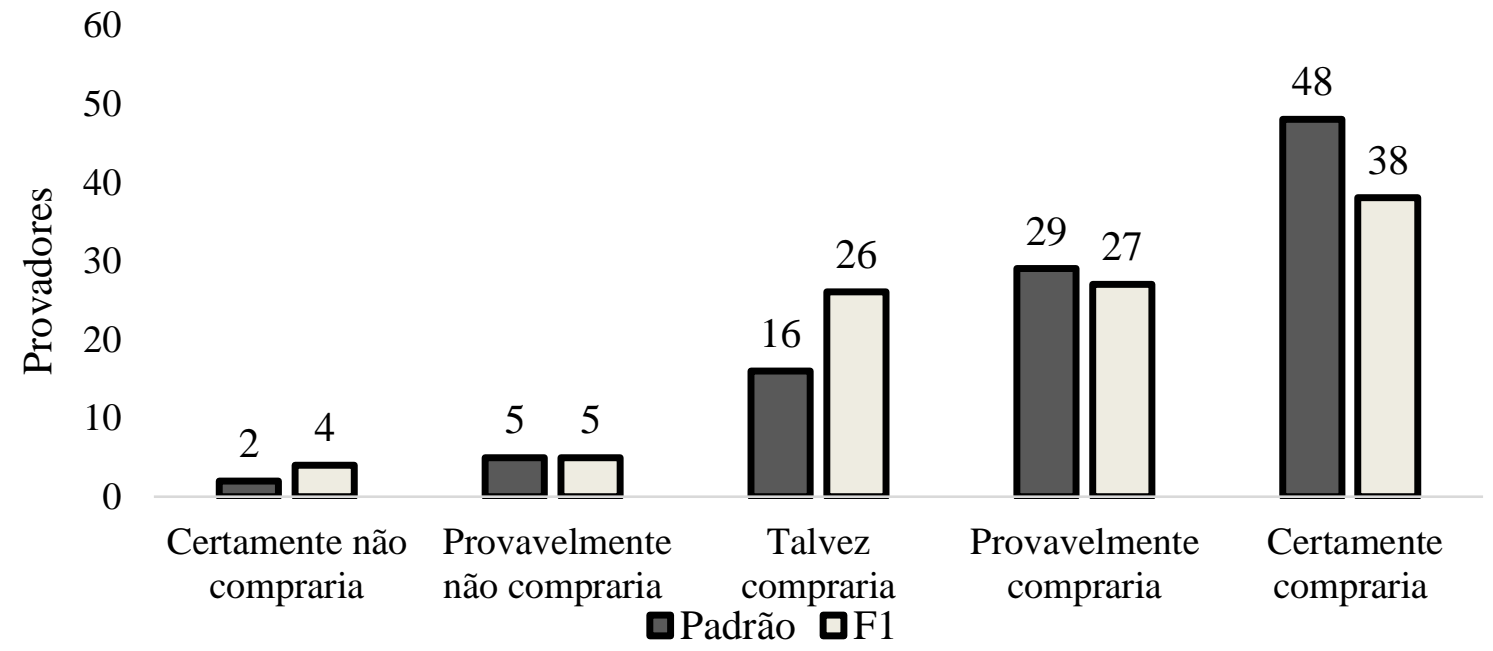

Figura 2 Intenção de compra das formulações padrão e light (F1) de doce de leite de cabra.

Para Palermo (2015), o teste de intenção de compra avalia se o consumidor compraria ou não o produto, sendo que uma intenção de compra positiva é dada com notas acima de 3 . Somando as notas positivas 5 (certamente compraria) e 4 (provavelmente compraria), a amostra padrão de doce de leite de cabra apresentou maiores notas correspondente à atitude positiva de compra, obtendo $77 \%$, enquanto que a amostra de doce light de leite de cabra apresentou $65 \%$ de intenção positiva de compra.
Resultados diferentes aos obtidos na presente pesquisa foram observados por Ribeiro et al. (2009), que desenvolveram duas formulações de doce de leite: uma convencional e outra diet (com adição de sucralose, Litesse ${ }^{\circledR}$ e Lactitol®). Em relação à intenção de compra dos doces, aproximadamente $88 \%$ dos provadores certamente ou provavelmente comprariam o doce de leite diet, enquanto $80 \%$ certamente ou provavelmente comprariam o doce de leite convencional. Estes resultados indicaram que o 
produto diet foi bem aceito pelos provadores e, consequentemente, teria boa aceitação no mercado.

Observou-se que, para ambas as formulações, os avaliadores relataram em seus comentários que os doces apresentavam sabor, aroma e textura diferenciada. Com relação ao sabor, explica-se pelo gosto característico e único do leite de cabra. Com relação à textura do doce de leite light, esta é obtida devido a menor quantidade de glóbulos de gorduras presentes no leite de cabra. Mesmo com esses relatos, não houve interferência significativa na aceitação do produto, tendo em vista os resultados satisfatórios observados.

Conforme os resultados obtidos, pode-se constatar que as duas formulações obtiveram um bom índice de aceitação e intenção de compra, demostrando assim que tanto a formulação de doce padrão de leite de cabra quanto à de doce light teriam grande probabilidade de aquisição, caso estivessem à venda no mercado.

\section{Conclusão}

De acordo com as características sensoriais, o doce light de leite de cabra desenvolvido apresentou uma boa aceitação e viabilidade para a comercialização, com boa qualidade microbiológica, além de apresentar uma redução no teor de carboidratos, tornando-se uma opção para os indivíduos que necessitam de alimentos para fins especiais ou que buscam uma alimentação mais saudável.

\section{Referências}

Albuquerque, A.; Cirino, A. C.; Martins, C.; Gomes, M. Influência do tipo de açúcar nas propriedades organolépticas do doce de leite. Nutrire, v. 36, n. 2, p. 60-60, 2011.

Alves, L. R. N.; Pinto, E. A. A.; Mendes, N. T.; Diniz, A. P. Inclusão de leite de cabra em merenda escolar. Sinapse Múltipla, v. 6, n. 1, p. 76-81, 2017. http://periodicos.pucminas.br/index.php/sinapsemultipla/a rticle/view/1542

American Public Health Association (APHA). Compendium of methods for the microbiological examination of foods. 4 ed. Washington, DC: American Public Health Association, 2001. 676p.
AOAC (Association of Official Analytical Chemists). Official methods of analysis, 16 ed. Arlington: AOAC, 2005.

Brasil. Conselho Nacional de Saúde. Resolução RDC $n^{\circ} 466$, de 12 de dezembro de 2012: aprova diretrizes e normas regulamentadoras de pesquisa envolvendo seres humano. Diário Oficial da União, Brasília, DF, 12 de dezembro de 2012.

Brasil. Ministério da Agricultura, Pecuária e Abastecimento. Portaria n. 354, de 04 de setembro de 1997. Aprova o Regulamento Técnico para Fixação de Identidade e Qualidade de Doce de Leite. Diário Oficial da República Federativa do Brasil, Brasília, 08 set. 1997. Seção 1, p. 19685.

Brasil. Ministério da Saúde. Agência Nacional de Vigilância Sanitária. Resolução RDC ANVISA/MS n ${ }^{\circ} .27$, de 13 de janeiro de 1998. Regulamento técnico referente a informação nutricional complementar. < http://portal.anvisa.gov.br/documents/33916/394219/POR TARIA_27_1998.pdf/72db7422-ee47-4527-9071859f1f7a5f29>

Brasil. Ministério da Saúde. Resolução n. ${ }^{\circ}$ 12, de 2 de janeiro de 2001. Regulamento técnico sobre os padrões microbiológicos para alimentos. Brasília, DF, 2001.

Brasil. Ministério da Saúde. Resolução nº 331, de 23 de dezembro de 2019. Regulamento técnico sobre os padrões microbiológicos para alimentos e sua aplicação. Diário Oficial da União, Brasília, 26 dez. 2019, Edição 249, Seção 1, p. 96.

Coelho, M. C. S. C.; Rodrigues, B. R.; Coelho, M. I. S.; Libório, R. C.; Costa, F. F. P.; Silva, G. L. Características físico-química e microbiológica do leite de cabra produzido em Petrolina-PE. Agropecuária Científica no Semiárido, v. 14, n. $\quad 3, \quad$ p. $175-182, \quad 2018$. http://dx.doi.org/10.30969/acsa.v14i3.965

Costa, L. F. X.; Oliveira, I. L. S.; Silva, I. C. A.; Moraes, J. P.; Silva, L. G.; Rodrigues, L. G. S.; Santos, A. L. B.; Costa, R. X. Análise sensorial de doce de leite elaborado com leite de cabra, acompanhado de calda de café. Vivências, v. 12 , n. 22, p. 60-69, 2016. http://www2.reitoria.uri.br/ vivencias/Numero_022/artig os/pdf/Artigo_06.pdf 
Dutcosky, S. D. Análise Sensorial de Alimentos. 4. ed. Curitiba: Champagnat, 2013. 513p.

Ferreira, L. O. Avaliação das características de qualidade de doces de leite comerciais. Revista Instantânea de Laticínios. "Cândido Tostes", v. 67, n. 387, p. 05-11, 2012. https://doi.org/10.5935/2238-6416.20120044

Garcia, P. P. C.; Carvalho, L. P. S. Análise da Rotulagem Nutricional de Alimentos diet e light. Ensaios e Ciências Biológicas, Agrárias e da Saúde, v. 15, n. 4, p. 89-103, 2011. https://www.redalyc.org/articulo.oa?id=26022135007

Granda, T.; Ramos, A. M.; Teixeiras, L. J. Q. Formulação e avaliação de doce de leite em pasta sem adição de açúcar. In: XXII Congresso Nacional de Laticínios. 12, 2013, Juiz de Fora. Anais do Congresso Nacional de Laticínios, Juiz de Fora: ANCL, v. 1, n. 2, p. 285-288, 2005.

Milagres, M.P; Dias, G.; Magalhães, M. A.; Silva, M. O.; Ramos, A. M. Análise físico-química e sensorial de doce de leite produzido sem adição de sacarose. Revista Ceres, v. 57, n. 4, p. 439445, 2010.

Palermo, J. R. Análise Sensorial: fundamentos e métodos. Rio de Janeiro: Atheneu, 2015.

Perrone, I. T., Stephani, R.; Neves, B. S. Doce de Leite: Aspectos Tecnológicos. Juiz de Fora: Instituto de Laticínios Cândido Tostes, v. 5, n. 3, 2011 .

Pieretti, G. G.; Seollin, V. J.; Bento, R. S.; Michika, J. N.; Santos, R. D.; Madrona, G. S. Doce de leite pastoso elaborado com açúcar mascavo: avaliação sensorial, físico-química e microbiológica. Revista Instantânea de Laticínios "Cândido Tostes", v. 68, n. 390, p.
59-64, 2012. https://doi.org/10.5935/22386416.20130009

Ribeiro, N. M. Q.; Costa, E. C. M.; Morais, A. S.; Rensi, C. M. V. B. Avaliação das Características Físico-Químicas e Sensoriais de Doce de Leite Diet Fabricado com Sucralose, Litesse ${ }^{\circledR}$ e Lactitol@. Unopar Científica. Ciências Biológicas e da Saúde, v. 11, n. 1, p. 21-25, 2009.

https://revista.pgsskroton.com/index.php/JHealthSci/articl e/view/1503/1441

Santi, L.; Berger, M.; Silva, W. O. B. Pectinases e pectina: aplicação comercial e potencial biotecnológico. Caderno pedagógico, v. 11, n. 1, p. 130-139, 2014. http://www.univates.br/revistas/index.php/cadped/article/ view/904/893

Silva, F. De A. S.; Azevedo, C.A.V. de. A new version of the Assistat -Statistical Assistance Software. In: WORLD CONGRESS ON COMPUTERS IN AGRICULTURE, 4., 2006, Orlando. Proceedings... Reno, RV: American Society of Agricultural and Biological Engineers, p. 393-396, 2006.

Silva, L. P. F. R.; Silva, S. N.; Alves, G. S.; Silva, E. V.; Vieira, A. F.; Costa, Z. R. T.; Gregório, M. G. Avaliação microbiológica e sensorial de cupcakes enriquecidos com a farinha do mesocarpo do coco. Magistra, v. 30, p. 376383 , 2019. https://magistraonline.ufrb.edu.br/index.php/magistra/arti cle/view/622

Watt, B.; Merrill, A. L. Composition of foods: raw, processed, prepared. Washington, DC: Consumer and Food Economics Research Division / Agricultural Research Service, 1963. 198p. (Agriculture Handbook, 8). 